\title{
SEO and Digital News Media: Visibility of Cultural Information in Spain's Leading Newspapers
}

\section{SEO i cibermitjans: visibilitat de la informació cultural dels principals diaris d'Espanya}

\author{
Carlos Lopezosa \\ Lluís Codina \\ Universitat Pompeu Fabra (Spain) \\ Mario Pérez-Montoro \\ Universitat de Barcelona (Spain)
}

This paper undertakes a comparative analysis of the visibility, and of other SEO indicators, of the culture sections of Spain's leading digital newspapers —specifically, elmundo.es, elpais. com, lavanguardia.com, abc.es, elconfidencial.com and 20minutos.esbased on data collected by the media analytics company, comscore, and the web traffic metric, Alexa Rank. The analysis employs a set of positioning indicators: namely, a visibility index, keywords, social signals, keyword profiles, URLS, SERP-Snippets, reference domains and best anchor texts, as made available by SISTRIX, an SEO analytics audit toolbox. Thus, we were able to determine which of the digital newspapers' culture sections has the best visibility. Likewise, we were able to identify which of these media are best positioned on Google, presumably as a result of more effective positioning strategies. We conclude with a discussion of our results
Aquest article realitza una anàlisi comparativa de visibilitat i altres indicadors SEO de la secció de cultura dels principals cibermitjans espanyols: elmundo.es, elpais.com, lavanguardia.com, abc. es, elconfidencial.com i 20minutos. es. Les anàlisis s'han dut a terme amb la utilització d'un conjunt d'indicadors de posicionament (visibilitat, paraules clau, senyals socials, paraules clau, url, snippets, dominis de referència i millors textos àncora) utilitzant l'eina de auditoria i anàlisi de posicionament en cercadors, SISTRIX. Ens preguntem quin d'aquests mitjans té millor una secció de notícies culturals amb millor visibilitat. L'estudi dut a terme amb els indicadors seleccionats permet, d'aquesta manera, presentar una anàlisi comparativa del periodisme cultural $i$ identificar quins d'aquests mitjans presenten millors posicions a Google, presumiblement, com a resultat d'estratègies de posicionament. Finalitzem amb una discussió 
and, on the basis of these findings, recommend ways in which the visibility of journalistic information can be optimised in search engines.

Keywords: digital news media, SEO, cultural journalism, analytics tools, Google. dels resultats juntament amb unes recomanacions finals per optimitzar la visibilitat de la informació periodística en els cercadors.

Paraules clau: cibermitjans, SEO, periodisme cultural, eines d'anàlisi, Google.

$\mathrm{M}$

ost of the world today explores the web using a search engine and, more particularly, the vast majority employ Google. This behaviour represents a significant challenge for the digital news media as they seek to position their news stories at the top of the search rankings in an attempt to win greater web visibility. To achieve this goal, one of the main strategies being adopted in the world's newsrooms is the application of search engine optimization (SEO) techniques.

The main objective of this study is to determine the visibility of the cultural journalism being undertaken by Spain's leading digital daily newspapers. Here, we focus our study on elmundo.es, elpais.com, lavanguardia.com, abc.es, elconfidencial.com, and 20minutos.es, the six papers with the greatest dissemination according to comScore (March 2018) and the Amazon Alexa Rank (May 2018). More specifically, we seek to analyse the positioning, together with other visibility indicators, of the cultural journalism of the aforementioned digital newspapers so as to identify which media firm is obtaining the best results in this field.

At the same time, as part of an ongoing line of research, we aim to further our attempts at developing protocols for the analysis of the visibility of digital news, using SEO analytics audit tools, in this case applied to the digital journalism sector. However, this study represents our first attempt at examining the daily press, a choice motivated by the fact that, despite the transformation experienced by the mass media in general, the daily papers selected here in representation of Spain's digital media continue to have a massive influence on public thinking and are typically considered as playing a fundamental role in the formation of opinion.

As such, the objectives of this study can be individually identified as follows:

1. To examine the feasibility of applying one of the main SEO audit tools to a study of the digital news media.

2. To determine which of the digital news media analysed have the best search engine positioning and to identify which indicators are best suited to analysing the visibility of these digital newspapers.

3. To undertake a comparative analysis of the main digital news media in the sector, with a specific focus on their respective culture sections. 
4. To generate SEO recommendations for the digital news media.

These objectives give rise to the following research questions:

2. If the above research question is shown to be possible, which indicators are best suited for undertaking a comparative analysis of the search engine visibility of these digital newspapers?

3. Based on the visibility patterns that emerge when applying the indicators identified in the above research question, what recommendations can be made to improve the search engine ranking of the different sections of the online media?

The following methodology has been employed in carrying out this study. First, an analytical review was undertaken of the academic literature on SEO and the digital news media (see articles included in the bibliography at the end of this paper). Second, we identified and selected a set of indicators of visibility and positioning as employed by the SISTRIX analytics toolbox. An initial version was applied in the study protocol and the results derived from this application were analysed. On the basis of these outcomes, a second, more precise, version was developed for the final analysis. Third, and finally, we applied this refined set of indicators to the digital newspapers previously selected, gathered the corresponding data, and analysed this information for further study and discussion.

\section{THEORETICAL FRAMEWORK}

Search engine optimization (SEO) comprises the set of procedures applied to a web page to boost its chances of appearing among the leading search results. This in turn means that this content enjoys greater online visibility and, as such, receives more web traffic. In the case of the news media, analysts report that the diversification of the newspaper sector on the Internet has meant many changes in the industry's routines, mainly propitiated by these new vectors for the dissemination of information, i.e. search engines (Smyrnaios and Rebillard, 2015).

With the emergence of news search engines, as early as 2007, more than one expert was warning that traditional journalistic practices would face severe challenges (Carlson, 2007), including the need to resort to SEO to maintain their social impact but without this meaning they would have to relinquish their traditional journalistic responsibilities.

The increase in online news has meant an increasing dependence of the news media on so-called digital platforms, including, search engines. From the point of view of newspaper publishers, this trend, in fact, represents a problem as well 
as a necessity (Smyrnaios, 2015), since much of their web traffic comes from the search engines. As such, the media are having to adapt.

Seen in a positive light, some authors argue that the role of search engines is to help people select the most relevant content (Machill et al., 2008) and this is why journalism should not overlook the importance of SEO actions. The question is that web visibility in the journalistic sector is essential for attracting more readers; hence, the importance now attached to making journalists understand the need to employ routines that integrate search engine positioning strategies (Giomelakis and Veglis, 2015).

But various studies on SEO and the media stress that there is still room for considerable improvement if current journalistic routines are to exploit the full potential of SEO routines (Smyrnaios and Sire 2014; Giomelakis and Veglis, 2015b). And while it is increasingly common to find SEO experts in newsrooms, there is still much work to be done to achieve a convergence between best journalistic practices and optimum SEO, because, among other factors, the sector is subject to constant change. In short, for journalism to adapt to the digital medium it must first adapt to the growing and changing needs of information visibility.

An aspect highlighted by more than one author (e.g. Dick, 2011) is that newsroom SEO practices around the world vary and their application is far from universal. Efforts to promote SEO practices are conditioned in any case by time, financial resources and management support, as well as by technical issues that might be unrelated to journalistic content (Dick, 2011).

Initial theoretical/practical encounters in the necessary relationship between journalistic and SEO principles arguably first occurred in 2009 (Asser, 2012) in the newsrooms of BBC News, with the introduction of the dual-headline system. This is characterized by the use of two headlines: on the one hand, the "newspaper headline" and, on the other, the "SEO headline". The former must obey journalistic routines, in other words, the style book of each medium, that is, a title that is optimised for the newspaper's readers. The latter, meanwhile, must be optimised for search engines and social networks. In technical terms, the newspaper headline is identified by the $\mathrm{h} 1 \mathrm{tag}$ of the markup language (HTML), while the SEO headline is identified by the metadata <title>. One is directly visible in the news story and on the media web page, and the other is directly visible to the search engines; indeed, the SEO title can only be seen by users if they search for it in the source code of the page.

According to available data, the development of this system meant that, between the second half of 2009 and the first half of 2011, visits to the news section of BBC News rose by $57 \%$, while visits to the whole web were up 34\%. Clearly, the SEO work undertaken by BBC News reaped its rewards. Elsewhere, the Reuters Institute Digital News Report (Newman and Levy, 2014), examining audiences in the United Kingdom, confirmed that 14\% of users seeking breaking news, did so using search engines.

These figures are a clear indication that journalists need to see SEO as a part of their journalistic work (Iglesias and Codina, 2016) and, more so, as part of the commitment of the media to their readers, because good SEO helps connect quality content with its audience. As various authors point out, search engines 
evaluate what content is useful for users by ranking that content in a higher position on their index (Norris, 2007). The higher the ranking of a digital news story on this index, the greater its visibility and the more web traffic (i.e. readers) it will attract.

This circumstance means, according to the studies cited here, that journalists writing in the digital news media have to write differently to those in the traditional media, i.e. they need to take into account search engine positioning strategies and implement SEO actions in their newsrooms.

Having presented the challenges posed by SEO and the digital news media, we next outline the principal SEO elements that experts in the field identify as being of importance for the digital news media. Here, a number of theoretical examples can be found, in the form of frameworks and recommendations, of the application of SEO in the newsrooms of the digital media carried out by leading scholars in the field of search engine positioning and digital newspapers.

It would appear that there is no consensus on just how to best apply SEO in digital journalism. However, it is not difficult to identify certain patterns and elements that have become standardised and which have been described by the main researchers in this field from 2008 to the present. As we have seen, a wellknown SEO strategy is the aforementioned dual-headline system (Asser, 2012) as employed originally by the BBC. As noted above, this system seeks to fulfil various goals: on the one hand, to provide the reader with the best headline, and, on the other, to provide the best SEO title to optimise search engine interpretation. This headline has to include the keywords in a prominent fashion so that the search engines prioritize the news story in their results (García and López, 2014).

In addition to the dual-headline system, other SEO techniques have been developed for the digital news media, such as those based on the so-called journalistic spheres (Smyrnaios and Sire, 2014). The first sphere involves the categorization of the news story, the second focuses on the news story itself, and the third is concerned with journalistic practices. First, the journalist needs to be aware of the specific theme to which his news story belongs (that is, how he might categorize it), since grouping it according to a particular theme gives it greater semantic value and can, according to the authors, improve its position within the search results (first sphere). The journalist must then consider the novelty of the news story, its originality, and the number of interactions generated in the social networks (second sphere) so as to be able estimate its main elements of interest. Finally, the journalist has to write the headlines using the keywords he has observed being used in the social networks. To do so he can take advantage of tools such as Google Insight, among others, to identify trends and see what topics the world is searching for. He can then apply them to his news story in order to achieve greater web visibility and, so, obtain more readers (third sphere).

As well as these three spheres, other ways of applying SEO to the digital news media are frequently included in studies and discussions on the subject. One of these is the distinction made between On-page, Off-page and Technical SEO (Giomelakis and Veglis, 2015; 2015a.). On-page SEO is the search engine positioning strategies carried out within the digital news media so that each of 
their news stories can improve its web visibility. Here, for example, the journalist would implement the dual-headline system (newspaper headline and SEO title); create news rich in keywords in the body of the article, provided this does not conflict with the newspapers' style guides (Richmond, 2008; Codina et al., 2016), include related keywords in the initial paragraphs (synonyms, plural variations, alternative forms, etc.) and use multimedia content in the form of photographs, videos, podcasts, etc. in each journalistic item (Giomelakis and Veglis, 2015a; 2015b).

Off-page SEO, on the other hand, refers to all those actions that are carried out off the web page and, as such, take place outside what is strictly the digital news media, but which nevertheless help position the news story. Here, the most widely accepted recommendation is that the digital news should strive to obtain as many quality external links (backlinks) as possible (that is, links from sites, which in turn are highly connected). To this end, the media need to promote and disseminate their news on the social platforms. This also implies carrying out a strategy of metadata adaptation, which differs depending on the social platform used. In turn, this involves using different SEO headlines and different descriptions (summaries) for each social network (Codina et al., 2016).

Finally, technical SEO defines how a website should be configured to help search engines interpret its content in an optimum fashion. In line with this definition, the digital news media should have a good information architecture, employ a correct source code (HTML) in its news stories and use meta descriptions (Giomelakis and Veglis, 2015a; 2015b). Technical SEO also requires the use of special formats for the mobile web, such as accelerated mobile pages or AMP (Heijmans, 2016), a technology created by Google to streamline a website and help a digital newspaper enhance its loading speed, obtain a better position in the search results and adapt to mobile device searches.

Although a set of best practices for search engine positioning can be identified, most authors claim that quality content remains the first requirement for SEO in the digital news media (Charlton, 2016). Indeed, in the absence of good editorial quality, it would not be possible to position a news story in an optimal fashion (Wordtracker, 2018): the higher the quality, the greater the possibilities of obtaining external links to other websites, which in turn will endow the content with greater authority and value, and ultimately result in enhanced search results.

In short, as we have seen, although many recommendations have been made as to how journalists should perform the tasks of SEO, a consensus has yet to be reached, apparently due to the complexity of the digital news media and their productive routines, and, also, perhaps because, these online newspapers remain reluctant to reveal successful solutions, in order to preserve their competitive advantage.

Given these circumstances, alternatives are available, such as SEO audit tools (García et al., 2016), which identify a set of both on-page and off-page SEO factors that can help identify and clarify the SEO strategies that might be applied in the digital news media. In short, they are tools that help show which media have achieved the best visibility and the factors directly underpinning this. 
On the basis of this initial set of known SEO strategies as applied to the news media, we have designed our study of six of Spain's leading digital newspapers, and more specifically of their respective culture sections. To do this, we have used the SISTRIX toolbox, one of the world's most frequently employed SEO audit tools and one that is widely implemented in the national media in Spain.

\section{METHODOLOGY}

In undertaking our analysis, we drew data from the following websites: elmundo.es, elpais.com, lavanguardia.com, abc.es, elconfidencial.com and 20minutos.es. All these portals were audited on 12 May 2018 by analysing the URL corresponding to their respective culture sections. We should stress, however, that the data obtained do not refer to just one sole day, but are longitudinal and refer to a range of time periods determined by the age of the URL.

This URL age is based on the inauguration date of the culture section of each of the newspapers analysed. For this purpose, we used Internet Archive (archive. org), the non-profit digital library dedicated to preserving archives and shots of public websites since 1996.

Therefore, although the analyses refer to a specific moment in time (May 2018), not only do they show stable results (although there may be small weekly fluctuations), they also show results from the cumulative activity of each site since being incorporated in Google's indexes. Indeed, in the case of these leading online papers one thing usually coincides with the other (as Google monitors the main media on a daily basis).

In order to illustrate each indicator, the following procedure was adopted: a review of the results provided by SISTRIX was first undertaken and then an analytical description was provided.

By proceeding in this fashion, we obtain dual results:

- We present a snapshot of the visibility of cultural journalism at a given moment in time. This picture is a cumulative - longitudinal- result, since the potential visibility of a website depends on its history since first being included in Google's index. In the case presented here, we are dealing with periods of several years, as is itemised in greater detail in the file card for each digital paper (we use the paper's first appearance in the archive.org library as a good approximation).

- We present a method for studying the visibility of journalistic information that has value in its own right, insofar as it can be replicated by other researchers, scholars or SEO professionals. The method can also be replicated for the taking of as many samples as necessary in accordance with the objectives of the study being conducted.

Here, we seek to obtain a picture of the comparative situations of the visibility of the respective culture sections of a group of digital newspapers at a given moment in time. Our aim in so doing is to determine the reasons why one newspa- 
48 per enjoys greater visibility than another. As such, we obtain cumulative - longitudinal- results of the URL of the culture section of each medium analysed since $\forall \quad$ its inclusion in Google's indexes.

Below, we present a set of file cards for each website in order to illustrate the specific components of our objects of study.

\begin{tabular}{|l|l|}
\hline \multicolumn{2}{l}{ Elmundo.es } \\
\hline Name & El Mundo \\
\hline Owner & Unidad Editorial \\
\hline URL & Spain \\
\hline comScore ranking & http://www.elmundo.es \\
\hline Alexa ranking & Ranked 1st (March 2018) \\
\hline Date first included in archive.org & Ranked 15th (May 2018) \\
\hline
\end{tabular}

Source: own elaboration.

\begin{tabular}{|l|l|}
\hline \multicolumn{2}{l}{ Elpais.com } \\
\hline Name & El País \\
\hline Owner & Grupo PRISA \\
\hline Country & Spain \\
\hline URL & https://elpais.com/ \\
\hline comScore ranking & Ranked 2nd (March 2018) \\
\hline Alexa ranking & Ranked 12th (May 2018) \\
\hline Date first included in archive.org & 29 September 2004 \\
\hline
\end{tabular}

Source: own elaboration.

\section{Lavanguardia.com}

\begin{tabular}{|l|l|}
\hline Name & La Vanguardia \\
\hline Owner & Grupo Godó \\
\hline Country & Spain \\
\hline URL & http://www.lavanguardia.com \\
\hline comScore ranking & Ranked 3rd (March 2018) \\
\hline Alexa ranking & Ranked 36th (May 2018) \\
\hline Date first included in archive.org & $\begin{array}{l}\text { The date is unavailable as the robots.txt file of lavanguardia. } \\
\text { com blocks the archive.org data collection service. }\end{array}$ \\
\hline
\end{tabular}




\section{Abc.es}

\begin{tabular}{|l|l|}
\hline Name & $A B C$ \\
\hline Owner & Vocento \\
\hline Country & Spain \\
\hline URL & http://www.abc.es \\
\hline comScore ranking & Ranked 4th (March 2018) \\
\hline Alexa ranking & Ranked 37th (May 2018) \\
\hline Date first included in archive.org & 27 March 1997 \\
\hline
\end{tabular}

Source: own elaboration.

\section{Elconfidencial.com}

\begin{tabular}{|l|l|}
\hline Name & El Confidencial \\
\hline Owner & Titania Compañía Editorial \\
\hline Country & Spain \\
\hline URL & https://www.elconfidencial.com \\
\hline comScore ranking & Ranked 5th (March 2018) \\
\hline Alexa ranking & Ranked 39th (May 2018) \\
\hline Date first included in archive.org & 29 April 2001 \\
\hline
\end{tabular}

Source: own elaboration.

\section{0minutos.es}

\begin{tabular}{|l|l|}
\hline Name & 20 Minutos \\
\hline Owner & Grupo Henneo \\
\hline Country & Spain \\
\hline URL & https://www.20minutos.es \\
\hline comScore ranking & Ranked 6th (March 2018) \\
\hline Alexa ranking & Ranked 51st (May 2018) \\
\hline Date first included in archive.org & 9 December 2002 \\
\hline
\end{tabular}

Source: own elaboration.

Next, we present a file card for the SEO audit toolbox used in this SEO analysis of cultural journalism in the digital news media and, then, we describe the main indicators used to analyse the culture sections of the digital newspapers selected. 


\begin{tabular}{|c|c|c|}
\hline 50 & Name & SISTRIX \\
\hline \multirow{3}{*}{ 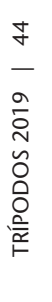 } & Owner & Firm of the same name \\
\hline & URL & https://www.sistrix.com \\
\hline & Description & $\begin{array}{l}\text { SISTRIX Toolbox is one of the best-known and most powerful SEO analytics } \\
\text { tools on the market. It has won numerous awards and is used in more than } 30 \\
\text { countries. Some of its features include its visibility index, keyword ranking, link } \\
\text { building analysis, On page SEO audit optimizer, social signal analysis and many } \\
\text { more. }\end{array}$ \\
\hline
\end{tabular}

Source: own elaboration.

To carry out the analysis of the culture sections of the main digital newspapers identified, we use the following indicators from the SISTRIX toolbox:

- SISTRIX visibility index: The SISTRIX visibility index is a key indicator of a domain's performance on Google. The rankings are weighted according to their search volume and position by keyword.

- Keywords: These values show how many keywords of a website (subdomain, subdirectory or URL) have been ranked in the top 100 positions in Google search results.

- Social signals: The number of social signals for the domain under evaluation. The Twitter, Facebook and Google+ platforms are evaluated. This indicator measures the number of interactions made by the followers of the social networks of each digital newspaper.

- Keyword profile: This details how many keyword rankings were among the top 10 Google searches and among the top 100 Google searches, as well as the average rank position.

- URLs: This describes how many different URLs of the audited domain are ranked in the top 10 ten and the top 100 Google rankings.

- SERP-Snippets: This identifies the rich search results appearing in the top 100 positions for the audited website.

- Reference domains: This list shows a cloud of domains that provide links to the web being analysed.

- Best anchor texts: This indicator details the most commonly used texts in hyperlinks that connect to the web under analysis.

\section{RESULTS}

A study of the culture sections of the digital newspapers selected with the Sistrix toolbox provided the following results: 


\begin{tabular}{|c|c|c|c|c|c|c|c|}
\hline פิ & $\stackrel{\Sigma}{=}$ & 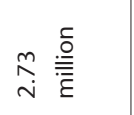 & $\begin{array}{l}\text { D } \\
\sim \\
\infty \\
\sim \\
\text { ஸे }\end{array}$ & 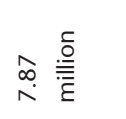 & 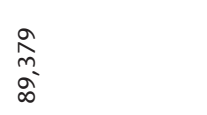 & 0 & \multirow{10}{*}{ 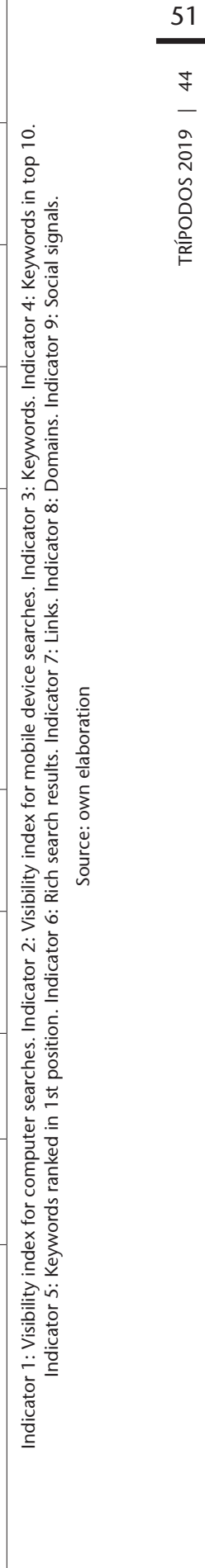 } \\
\hline$\stackrel{\infty}{\subseteq}$ & $\stackrel{n}{2}$ & $\stackrel{\infty}{\widetilde{N}} \stackrel{0}{=}$ & $\stackrel{m}{\sim}$ & 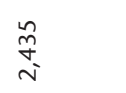 & $\stackrel{\hat{m}}{r}$ & $\wedge$ & \\
\hline$\underline{\underline{\Xi}}$ & $\stackrel{N}{\check{E}}$ & 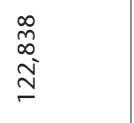 & $\stackrel{\infty}{\sim}$ & $\begin{array}{l}\stackrel{\bar{\infty}}{N} \\
\stackrel{\sim}{N}\end{array}$ & $\stackrel{\text { qu }}{\circ}$ & $\widetilde{\mathscr{\gamma}}$ & \\
\hline$\stackrel{\text { Io }}{ }$ & 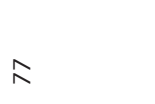 & $\underset{\substack{\stackrel{ \pm}{N} \\
\stackrel{m}{+}}}{ }$ & $\tilde{\sim}$ & $\begin{array}{l}\hat{0} \\
\text { ò. } \\
\text { in }\end{array}$ & \begin{tabular}{l}
\multirow{l}{n}{} \\
$\infty$ \\
0 \\
0
\end{tabular} & \pm & \\
\hline$\stackrel{n}{\underline{s}}$ & 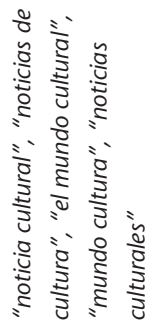 & 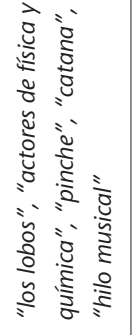 & 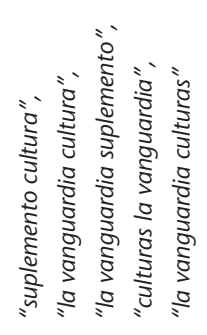 & 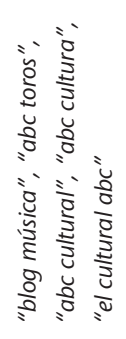 & 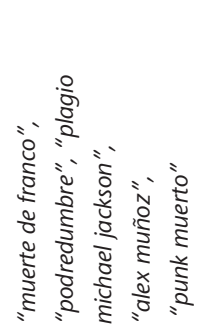 & 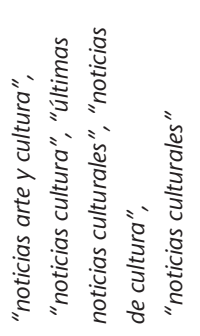 & \\
\hline$\stackrel{\Xi}{\Xi}$ & $n$ & 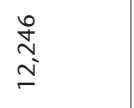 & $\stackrel{\circ}{\circ}$ & $\begin{array}{l}\infty \\
\alpha \\
i\end{array}$ & $\underset{\underset{\infty}{\sim}}{\stackrel{\sim}{\sim}}$ & $\bar{N}$ & \\
\hline$\stackrel{m}{\underline{m}}$ & F్ & $\begin{array}{l}\stackrel{2}{\alpha} \\
\text { à }\end{array}$ & $\approx$ & 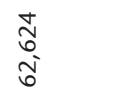 & $\begin{array}{l}0 \\
\infty \\
\infty \\
\\
\end{array}$ & సे & \\
\hline$\stackrel{N}{\subseteq}$ & 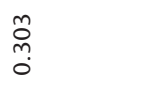 & $\begin{array}{l}\text { gे } \\
\text { ò }\end{array}$ & ָ̃ & 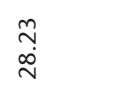 & $\frac{\bar{\sigma}}{0}$ & 0 & \\
\hline$\underline{\underline{E}}$ & $\stackrel{\widetilde{N}}{\tilde{0}}$ & $\bar{N}$ & $\underset{\sim}{\tilde{n}}$ & 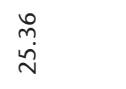 & $\underset{\sim}{\tilde{\infty}}$ & $\underset{\widetilde{\sigma}}{\tilde{\sigma}}$ & \\
\hline & 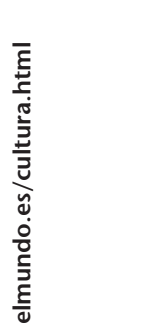 & 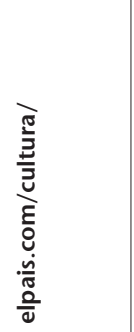 & 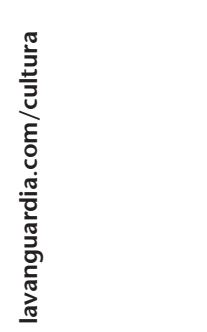 & 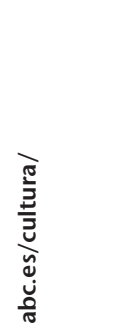 & 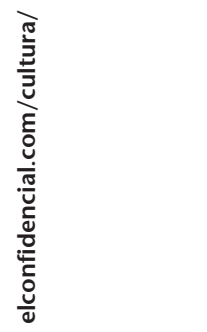 & 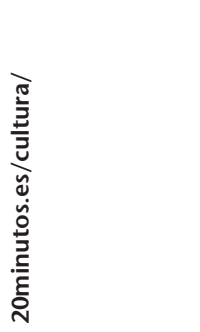 & \\
\hline
\end{tabular}


52 Next, we describe in detail the main results obtained from the study of these digital newspapers with the SISTRIX toolbox:

\section{Figure 1. Visibility index results of the culture sections for computer searches}

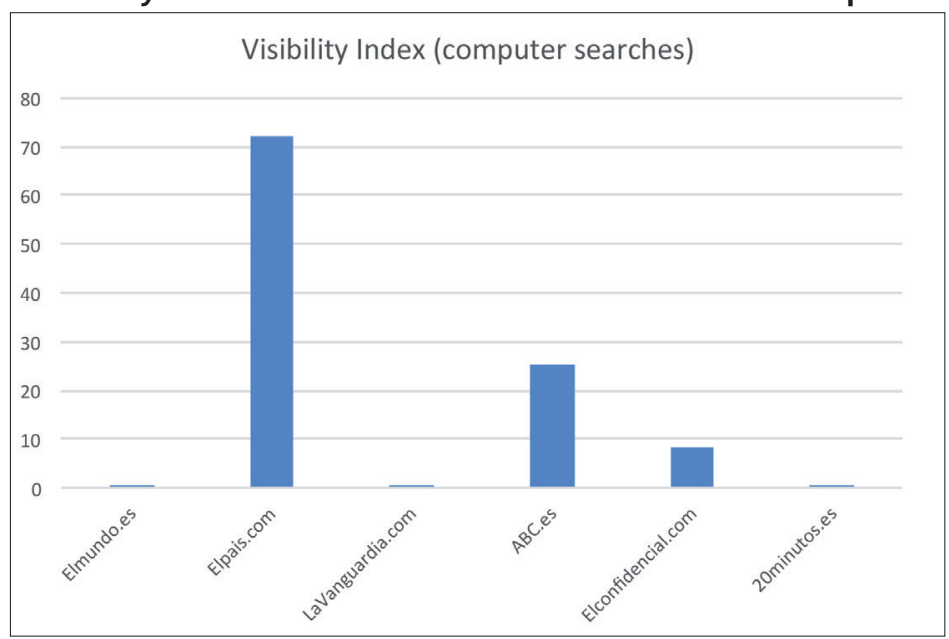

Source: own elaboration.

Elpais.com is the site with the highest visibility index (72.1 points), a score based on computer searches for the URL of its culture section. It is followed by ABC.es with a score of 25.36 and elconfidencial.com with a score of 8.235. The visibility index can be considered a key indicator of URL performance and constitutes the sum of search volumes and keyword rankings.

Figure 2. Visibility index results of the culture sections for mobile device searches

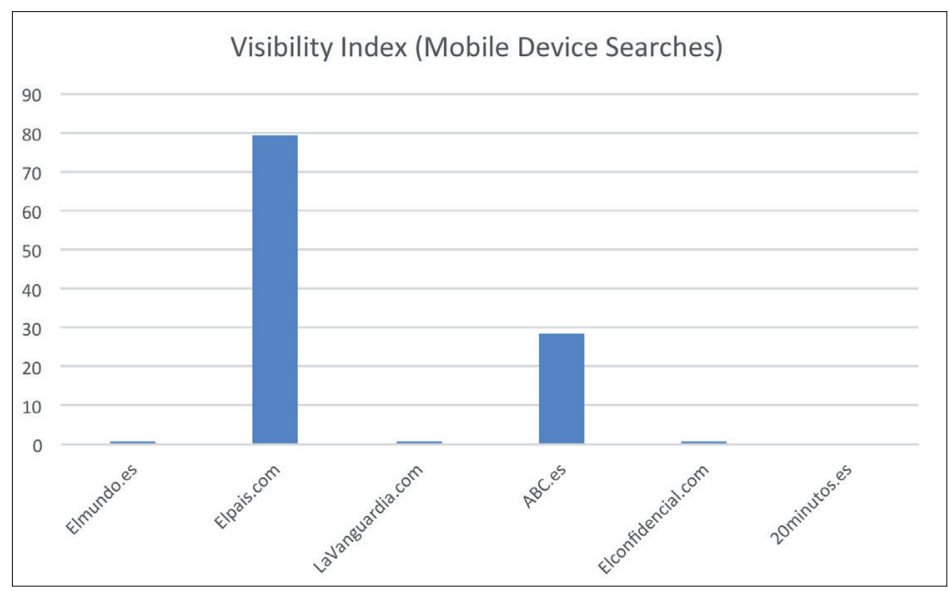

Source: own elaboration. 
Elpais.com is also the site with the highest visibility index (79.49 points) for mobile device searches for the URL of its culture section. It is followed by ABC.es with a score of 28.23 and elmundo.es with a score of 0.303 .

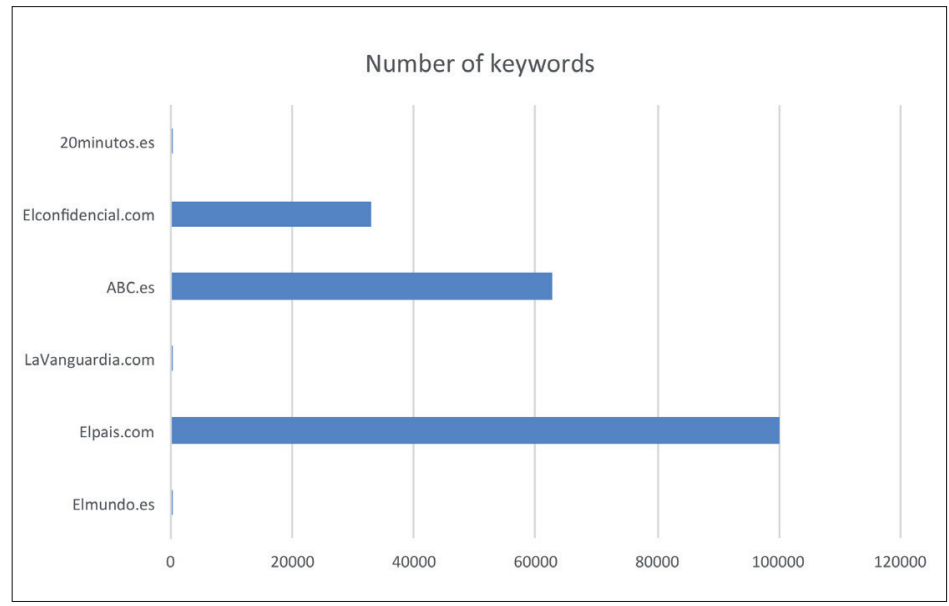

Source: own elaboration.

Elpais.com is the site with the most keywords $(99,970)$ ranked among Google's top 100 results for the URL of its culture section. It is followed by ABC.es with 62,624 keywords and elconfidencial.com with 32,836 keywords.

Figure 4. Number of keywords ranked among Google's top 10 searches for the culture sections of each digital newspaper analysed

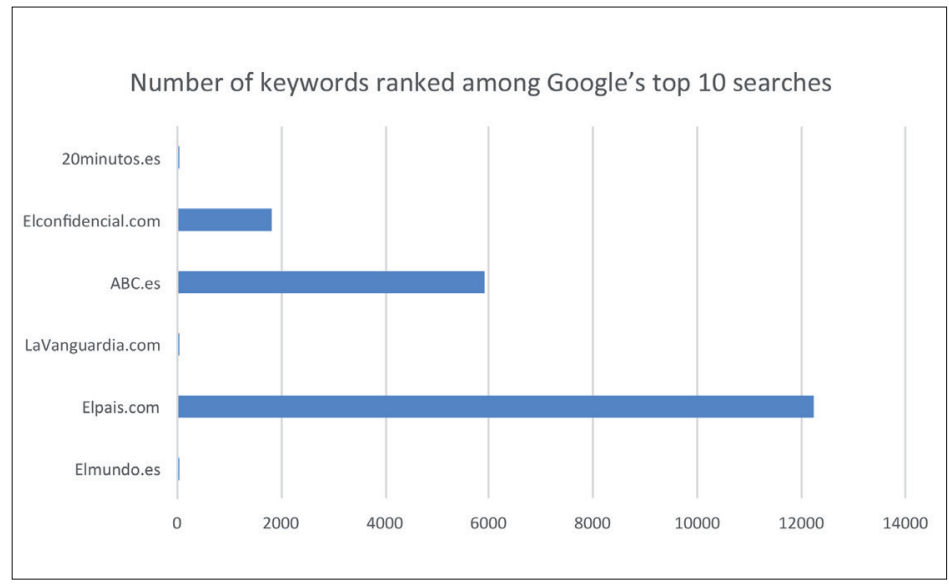

Source: own elaboration. 
Elpais.com is the portal with the most keywords $(12,246)$ ranked among Google's top 10 searches for the URL of its culture section. It is followed by ABC.es with 5,918 keywords and elconfidencial.com with 1,822 keywords.

The principal keywords ranked in first position for the culture sections of the digital newspapers analysed have three main characteristics in common, tending to be:

- Informational keywords that identify specific elements related to culture, art, cinema, music, etc.

- Keywords that identify specific elements related to the actual culture section of the newspaper in question, such as "noticias de cultura" (cultural news) "suplemento de cultura" (culture supplement), etc.

- Keywords that identify the newspaper by name plus the section or type of news, such as "el mundo cultura", "la vanguardia cultura", "abc cultural", etc.

Figure 5. Volume of rich search results for the culture sections of each digital newspaper analysed

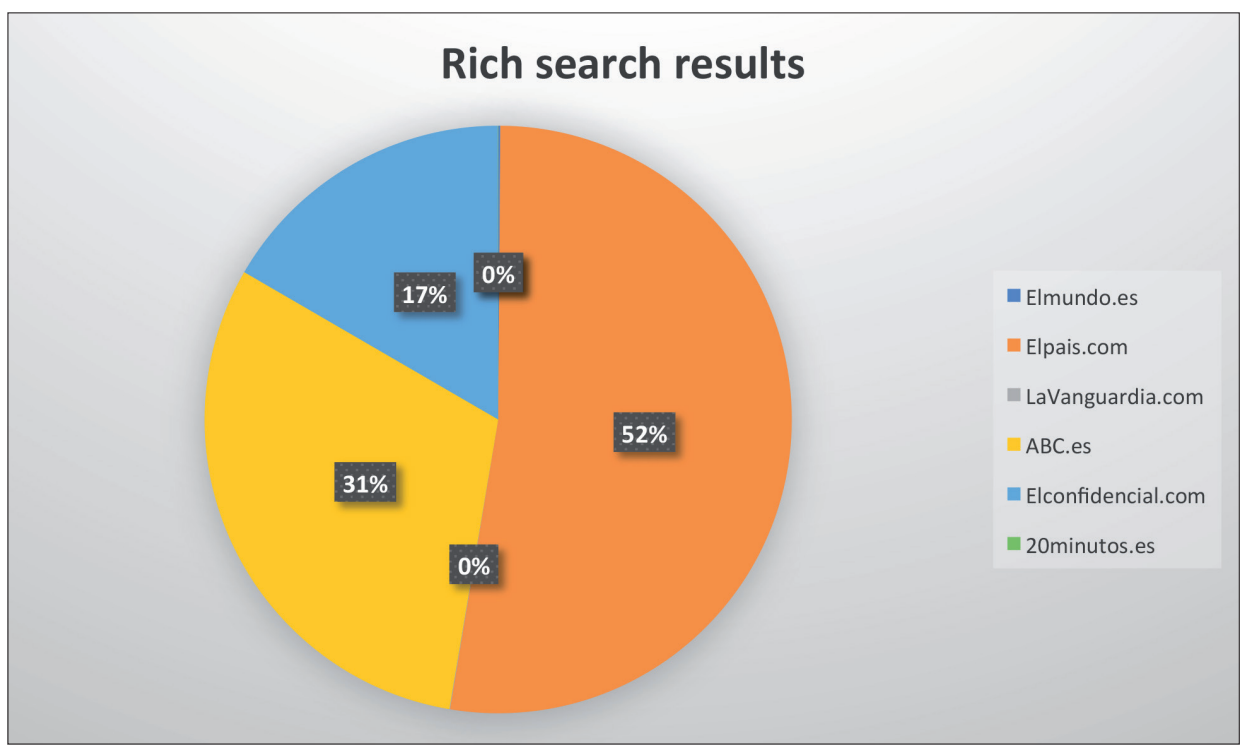

Source: own elaboration.

Elpais.com is the site with the highest number of rich search results $(34,274)$ for the URL of its culture section. It is followed by ABC.es with 20,037 and elconfidencial.com with 10,845 . The main rich search results take the form of knowledge graphs, images plus result, rich snippets and results with a direct response. 
Figure 6. Number of external hyperlinks received by the culture sections

of each digital newspaper analysed

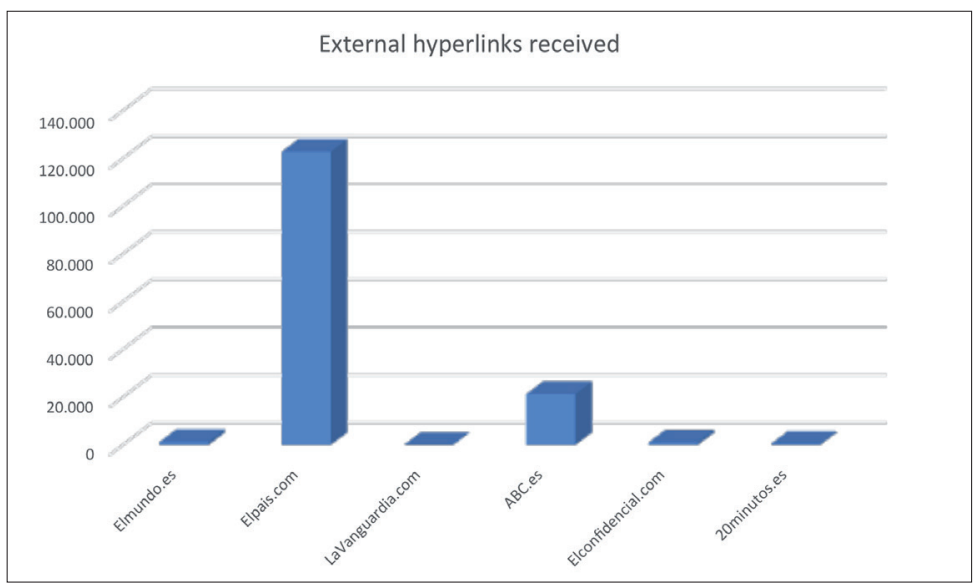

Source: own elaboration.

Elpais.com is the site that received the most external hyperlinks $(122,836$ originating form 1,528 domains) connecting to the URL of its culture section. It is followed by ABC.es with 21,281 links originating from 2,435 domains, and elmundo.es with 1,172 links originating from 15 domains.

Figure 7. Number of external domains that link to the culture sections of each digital newspaper analysed

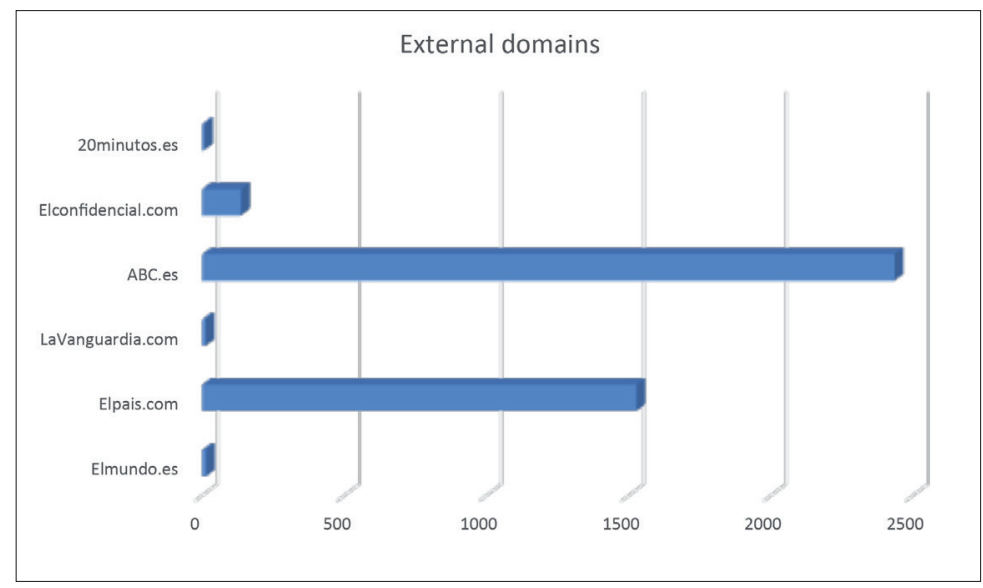

Source: own elaboration.

If we consider the specific dimension of the relationship between the hyperlinks and their anchor texts, our data show that the links received by the culture sections of all the digital newspapers analysed here are natural occurrences, since 
56 the anchor text in each of them is represented by the name of the digital newspaper, or directly by the URL of their respective culture sections.

Figure 8. Social interactions on the social networks of the culture sections of each digital newspaper analysed

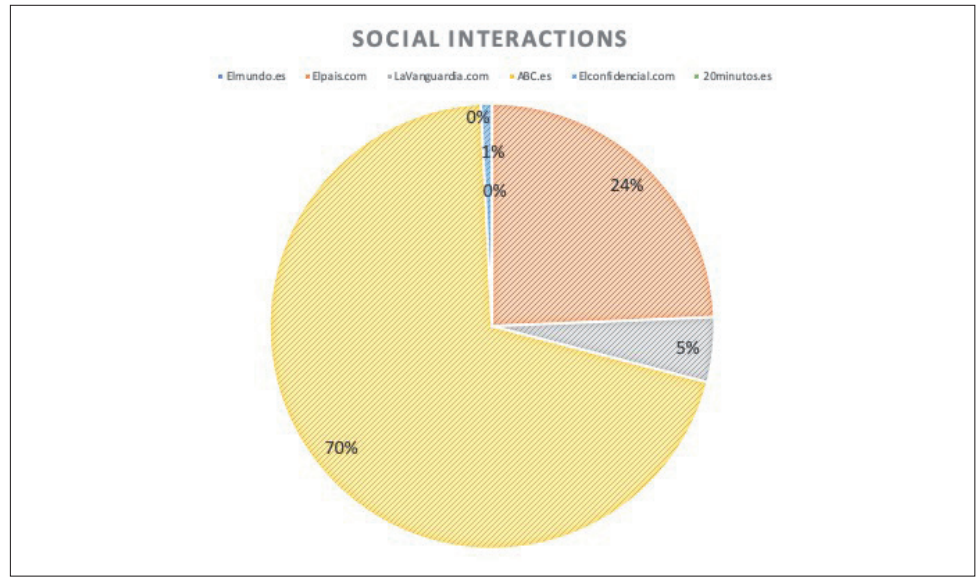

Source: own elaboration

Abc.es is the site with the best social network diffusion (7.87 million points) based on the URL of its culture section. It is followed by elpais.com with 2.73 million points, and lavanguardia.com with 528,280 points. These values indicate the number of social signals obtained from the domain under evaluation.

Next, we show, based on the principal findings obtained from the study of these digital news media with the SISTRIX toolbox, the meaning of these outcomes at the broader strategic level.

\section{DISCUSSION}

Based on the results obtained, it can be seen that elpais.com, abc.es and elconfidencial.com are the digital newspapers that enjoy the highest level of visibility as far as their respective culture sections are concerned. Evidence of this is the marked difference between these three media and the other three newspapers analysed here in terms of the visibility index and the number of keywords ranked among Google's top 100 search results.

The key question is whether these media are employing a specific strategy of visibility? We cannot determine this for sure, but it seems more than likely given the difficulty of achieving good results on Google pages in the absence of such a strategy. Here, the strategic difference in the comparative visibility between the digital newspapers is highlighted by the difference in the number of words located in the top 100 positions between those with the best visibility and those with the worst visibility. For example, the culture section of elpais.com (the URL 
with the best SEO performance) has 99,970 words, while the culture section of 20minutos.es (the URL with the worst SEO performance) has just 29 keywords.

We have also been able to see that the SEO analytics tools enable those responsible for the positioning and visibility of journalistic productions to know in detail the exact situation in which their sections find themselves and to take appropriate decisions (after all, "what is not measured cannot be improved").

The SISTRIX toolbox has allowed us to determine the state of the SEO health of the culture sections of these digital newspapers. The culture section of elpais. com is the one in best health based on its visibility - the proof lying in its metrics-. For example, it obtained the highest visibility index for both computer and mobile device searches, it also recorded the highest number of keywords ranked among Google's top 100 and top 10, and had the highest number of rich search results and the highest number of hyperlinks received.

Having examined the different dimensions of the foregoing findings, in the following section -our conclusions - we re-examine our research objectives and research questions in the light of these results.

\section{CONCLUSIONS}

To complete the discussion, and to determine what conclusions might be drawn, we first return to the objectives identified at the start of this study to consider just how well the above analysis has been able to meet them. We then do the same with the three specific research questions raised.

Objective 1. To examine the feasibility of applying one of the main SEO audit tools to a study of the digital news media.

We have been able to verify that a tool such as SISTRIX provides a set of indicators that are capable of analysing aspects of the visibility and positioning of the digital news media and the sections of their online newspapers. Specifically, we have been able to determine patterns of SEO strategies as highlighted in the results and in our discussion of these outcomes.

Objective 2. To determine which of the digital news media analysed have the best search engine positioning and to identify which indicators are best suited to analysing the visibility of these digital newspapers.

We have shown that the culture sections of elpais.com, abc.es and elconfidencial. com have the highest visibility. Evidence of this is provided by their respective scores on the visibility index, and the number of keywords ranked among Google's top 100 search results. These two factors, together with that of hyperlinks, are the main indicators to take into account in such a study. 
Objective 3. To undertake a comparative analysis of the main digital news media in the sector, with a specific focus on their respective culture sections.

We have demonstrated the feasibility of carrying out a comparative study of the digital news media using the SISTRIX toolbox, based on the results of its visibility index, keyword rankings, rich results, inbound hyperlinks, and the score awarded to social network signals. We have shown that elpais.com is the online newspaper that has the culture section with the highest level of visibility. In contrast, the culture section of 20minutos.es performs worst in terms of search engine visibility.

Objective 4. To generate SEO recommendations for the digital news media.

Conducting a comparative study using the SISTRIX toolbox on the different digital newspapers is feasible, since it allows us to screen for many elements that illustrate why one website is better positioned than another.

Indicators such as the visibility index for both mobile devices and computers, the number of ranked keywords, inbound hyperlinks, rich search results obtained, and the number of social signals received are the elements that allow us to perform a comparative analysis.

\section{QUESTIONS AND FUTURE AVENUES OF RESEARCH}

Question 1. Can an SEO analytics tool be used to carry out a comparative analysis of the positioning of six leading digital newspapers and, more specifically, of their respective culture sections?

The wealth and breadth of the information obtained in the analysis reported above allow us to respond positively to this question. The tool employed has enabled us to determine which of the digital newspapers' culture sections has the best search engine positioning, which receives most visits as a result of its having most keywords ranked among Google's top 100 results, which has obtained the best rich search results, which has received the most and best links from other websites and, in short, which have undertaken SEO work on their culture section and which have not.

Question 2. If the above research question is shown to be possible, which indicators are best suited for undertaking a comparative analysis of the search engine visibility of these digital newspapers?

Our results show that the main indicators to consider when performing a comparative analysis are the visibility index, the number of keywords ranking among Google's top 100 search results, the number of links received, and the number of rich results obtained. 
Question 3. Based on the visibility patterns that emerge when applying the indicators identified in the above research question, what recommendations can be made to improve the search engine ranking of the different sections of the online media?

Our results identify the use of certain visibility strategies which, in turn, allows us to understand some of the patterns that emerge from our comparative analysis. For example, the fact that digital newspapers such as elpais.com, abc.es, and elconfidencial.com have so many keywords ranked among Google's top 100 results shows they implement SEO actions that focus on the respective URLs of their culture sections and, in this way, they are able to generate a considerable volume of reader traffic thanks to the quality of these sections and their search engine visibility.

In the specific case of the SISTRIX analytics tool, we have demonstrated that it provides a number of highly insightful indicators of visibility, including, most specifically, the number of keywords, inbound links and rich results, which enable us to identify which of the digital media sites receive most web traffic.

By employing tools such as SISTRIX and by undertaking the type of analysis reported in this study, the digital news media are capable of designing better strategies to boost the readership of their different sections.

\section{FUTURE LINES OF RESEARCH}

The digital news media is a sector of great social and cultural importance, so that any study of online newspapers, visibility and SEO, are of great relevance and can, we believe, be of great use to the sector itself given its present impact on society.

The potential for developing future research lines is enormous but we shall limit ourselves here to just a few. For example, future studies might usefully compare other sections of these or other digital newspapers, or they might opt to analyse the positioning strategies of their front pages. Finally, new methodologies might be adopted in undertaking analyses of the digital news media, which combined with the use of SEO tools, would enable us to explore the direct link between positioning strategies and the results of the indicators employed by these tools.

Carlos Lopezosa (carlos.lopezosa@upf.edu) is a researcher in the Doctorate Programme of the Department of Communication of the Universitat Pompeu Fabra (UPF) and a collaborator of the DigiDoc (Digital Documentation and Interacti- ve Communication Research Group). He is carrying a doctoral thesis on SEO and online news media. He is an assistant professor in Search engine Optimization at the Barcelona School of Management of the Universitat Pompeu Fabra. 
Lluís Codina (lluis.codina@upf.edu) holds a $\mathrm{PhD}$ in Information Science from Autonomous University of Barcelona. He is a Professor at the Universitat Pompeu Fabra in Barcelona. He teaches in the School of Communication at Journalism and Communication Studies and the Master's Degree in

Mario Pérez-Montoro (perez-montoro@ ub.edu) holds a PhD in Philosophy and Education from the University of Barcelona (Spain) and a Master in Information Management and Systems from the Polytechnic University of Catalonia (Spain). He studied at the Istituto di Discipline della Comunicazione at the Università di Bologna (Italy) and has been a Visiting
Social Communication (MUCS) Department of Communication. He is the coordinator of the Digital Documentation and Interactive Communication Group of the Pompeu Fabra University. His research work is focused in digital and interactive information systems.

Scholar at the Center for the Study of Language and Information (CSLI) at Stanford University (California, USA) and at the School of Information at UC Berkeley (California, USA). He is a Professor in the Department of Information Science at the University of Barcelona (Spain). His work has focused on information architecture and visualization.

\section{References}

Asser, M. (2012). "Search Engine Optimisation in BBC News". BBC. Available at: <http:// www.bbc.co.uk/blogs/bbcinternet/2012/09/ search_engine_optimisationin.html>. Accessed 12 June 2018.

Carlson, M. (2007). "Order Versus Access: News Search Engines and the Challenge to Traditional Journalistic Roles". Media, Culture \& Society, 29, pp. 1014-1030.

Charlton, G. (2016). "How Much do Journalists and Editors Need to Know about SEO?". Search Engine Watch. Available at: <https:// searchenginewatch.com/2016/03/15/howmuch-do-journalists-and-editors-need-toknow-about-seo/>. Accessed 12 June 2018.

Codina, L. [et al.] (2016). Visibilidad y posicionamiento web de informaciones periodísticas: el 'framework' SEO-RCP. Barcelona: Universitat Pompeu Fabra. Departament de Comunicació.

Dick, M. (2011). "Search Engine Optimization in UK News Production". Journalism Practice, 5 (4), pp. 462-47.
García, L. [et al.] (2016). "Herramientas e indicadores SEO: características y aplicación para análisis de cibermedios". El Profesional de la Información, 25 (3), pp. 497-504.

García, B. and López X. (2014). "Headlines in Major European Digital Media in Europe: More Functional than Conceptual". Estudios sobre el Mensaje Periodístico, 25(2), pp. 833-847.

Giomelakis, D. and Veglis, A. (2015a). "Employing Search Engine Optimization Techniques in Online News". Studies in Media and Communication, 3 (1), pp. 22-33.

-. (215b). "Investigating Search Engine Optimization Factors in Media Websites: The Case of Greece". Digital Journalism, 4(3), pp. 379-400.

Heijmans, M. (2016). "What To Do to Optimize Your News Site For SEO". Search Engine Journal. Available at: <https://www. searchenginejournal.com/optimizing-newssite/168831>. Accessed 14 June 2018. 
Iglesias, M. and Codina, L. (2016). "Los cibermedios y la importancia estratégica del posicionamiento en buscadores (SEO)". Opción, 32 (9), pp. 929-944.

Machill, M.; Beiler, M., and Zenke, M. (2008). "Search-Engine Research: A European-American Overview and Systematization of an Interdisciplinary and International Research Field". Sage Journals, 30(5), pp. 591-608.

Newman, N. and David L. (2014). Reuters Institute Digital News Report 2014. Tracking the Future of News. United Kingdom: Reuters Institute for the Study of Journalism, University of Oxford.

Norris, C. (2007). "SEO For Journalists: Introduction and Keywords". MOZ. Available at: <https://moz.com/ugc/seo-forjournalists-introduction-keywords-part1-of-5>. Accessed 14 June 2018.
Richmond, S. (2008). "How SEO Is Changing Journalism". British Journalism Review, 19, pp. 51-55.

Smyrnaios, N. (2015). "Google and the Algorithmic Infomediation of News". Media Fields Journal, 10, pp. 1-10.

Smyrnaios, N. and Rebillard, F. (2009). "L'actualité selon Google. L'emprise du principal moteur de recherche sur l'information en ligne". Communication et Langages, 160, pp. 95-109.

Smyrnaios, N. and Sire, G. (2014) "The News According to Google How Does Algorithmic Infomediation Frame the Work of French Journalists?". Presented at JSS-ECREA 2014 Conference. Thessaloniki: March 27-29.

Wordtracker (2018). "A Guide to SEO for Editorial Teams and Journalists". Wordtracker. Available at: <https://www.wordtracker.com/ academy/seo/getting-started/seo-for-editorialteams-journalists>. Accessed 16 June 2018. 
